\title{
Long-lasting adverse effects after short-term low-dose treatment with metoclopramide for vomiting
}

\author{
Eilif Dahl ${ }^{1}$, Arthur L. Diskin ${ }^{2}$ \\ ${ }^{1}$ Department of Occupational Medicine, Haukeland University Hospital, Norwegian Centre for Maritime Medicine, Bergen, Norway \\ ${ }^{2}$ Azamara Club Cruises, Celebrity Cruises, Royal Caribbean International, Medical and Public Health, Miami, Florida, USA
}

\begin{abstract}
Metoclopramide is commonly used to treat vomiting caused by seasickness and acute gastroenteritis on cruise ships and serious adverse effects have not been reported from use at sea. We report severe long -lasting adverse effects in a young female seafarer following short-term, low-dose use of metoclopramide. During rough seas a 25-year-old female musician on a cruise vessel presented with nausea and vomiting. She was given intramuscular metoclopramide $10 \mathrm{mg}$ and diphenhydramine $25 \mathrm{mg}$. Vomiting stopped after the injections, but she felt tired, confused and dizzy. She then had been taking metoclopramide 5-10 mg a day, but stopped after a total per oral dose of $30 \mathrm{mg}$ as she developed disturbing symptoms that she related to the medication, including dizziness, anxiety, fatigue, depression and involuntary movements (twitches, jerks, ticks, and tremors of the eyelids, tongue, neck, fingers, arms and legs). Neurological examination, blood tests, electrocardiography and magnetic resonance imaging of the brain were all normal. Although gradually reduced in strength and frequency, the adverse effects were very disturbing for about 10 months, but at 13 months she was almost fully recovered.

For many years numerous vomiting sea travellers have been successfully treated with a single parenteral $10 \mathrm{mg}$ dose of metoclopramide. There are no obvious reasons why our previously healthy patient experienced such serious and long-lasting side effects after low-dose, short-term metoclopramide administration. Until more is known, metoclopramide should be reserved for debilitating cases - and only be given after other remedies have been tried and found ineffective.
\end{abstract}

(Int Marit Health 2014; 65, 1: 16-19)

Key words: vomiting, seasickness, metoclopramide, adverse effects

\section{INTRODUCTION}

Vomiting is an unpleasant and sometimes debilitating symptom of motion sickness and acute gastroenteritis, 2 conditions that can easily ruin the cruise for ill passengers and represent a safety hazard when officers and crew are affected. Severely seasick patients have been found to respond quickly to a single dose of parenteral metoclopramide [1], which has been widely used against vomiting in the international cruise industry. Adverse effects have not been reported from use at sea, but land reports show an increased risk for tardive dyskinesia with duration of treatment and total cumulative dose. This caused the European
Medicines Agency in 2013 to recommend changes to the use of metoclopramide, including narrowing the indications for use and restricting the maximum daily dose to a total of $30 \mathrm{mg}$ for a maximum of 5 days in adults [2]. We report severe adverse effects in a young female seafarer following short-term, low-dose use of metoclopramide.

\section{CASE REPORT}

A 25-year-old female musician on a cruise vessel had a non-alcoholic beverage (mango lassi) ashore, later drank a few glasses of wine aboard, which was unusual for her, and when she went to bed, she felt quite dizzy. During that 
night the sea was rough and in the early morning she presented in the Medical Centre aboard with vertigo, nausea and vomiting. She was given intramuscular metoclopramide $10 \mathrm{mg}$ and diphenhydramine $25 \mathrm{mg}$. Immediately after the injections she felt very tired and confused. The vomiting stopped, but vertigo persisted. She had been sleeping most of the day. In the afternoon her condition was diagnosed as possible gastroenteritis and metoclopramide tablets, $10 \mathrm{mg}$ twice a day, were prescribed. Shortly after taking only $1 / 2$ tablet ( $5 \mathrm{mg}$ ), she felt faint and anxious, but brushed this off as 'just being sick'. After taking another $5 \mathrm{mg}$ at night she felt very anxious, dizzy and weak, but also like her body was about to explode. The next day she felt just as bad, thought she was still seasick and took $5 \mathrm{mg}$ metoclopramide twice that day. The third day she did not take any metoclopramide. The fourth day she took $10 \mathrm{mg}$ metoclopramide in the evening, and shortly after she had irrational, compulsive suicidal thoughts that terrified her; she felt her heart racing and had strange somatic sensations, but at that point she believed that her symptoms were caused by the medication. Therefore, after a total of $40 \mathrm{mg}$ metoclopramide $(10 \mathrm{mg}$ intramuscular $+30 \mathrm{mg}$ by mouth) administered over 4 days, metoclopramide was stopped. However, she continued to experience disturbing symptoms that she related to the medication almost every day, including dizziness, anxiety, and depression, as well as involuntary movements (twitches, jerks, ticks, and tremors of the eyelids, tongue, neck, fingers, arms and legs) lasting seconds to minutes (Table 1) [3]. She 'took a lot of diphenhydramine' at first, and later occasionally, which helped her to sleep, but her mental and somatic symptoms continued. She was able to work, but felt at times that she did not have proper control over her finger movements while playing her instrument.

Her weight was $56 \mathrm{~kg}$. Her vital signs, neurological exam, blood and urine chemistry, and electrocardiography done on board were normal.

She was referred to a neurologist consultant in port who agreed with the ship's diagnosis of adverse metoclopramide effects. An magnetic resonance imaging stroke screen was normal.

She had previously been healthy and did not use any medications or drugs. At the age of 13 she had been in a serious traffic accident and afterwards received posttraumatic stress syndrome counselling for years.

For about 10 months after metoclopramide she still experienced anxiety, near-panic attacks, nightmares, fatigue and episodes of depression. The involuntary movements were gradually reduced in strength and frequency. However, at 13-month-follow-up she was optimistic regarding a complete recovery: only slight mental dullness remained, she slept well and felt only rarely 'some really tiny twitches all over my body'.
Table 1. Twenty-three adverse effects experienced by our patient - from a list of 38 rare metoclopramide side effects that should cause patients to check with their doctor immediately if any of them occurs, according to US National Library [3]

Abdominal or stomach pain or tenderness
Chills
Difficulty with breathing
Difficulty with speaking or swallowing
Dizziness or fainting
Fast or irregular heartbeat
General feeling of tiredness or weakness
Headache (severe or continuing)
Increased sweating
Lip smacking or puckering
Loss of appetite
Loss of bladder control
Mask-like face
Muscle spasms of the face, neck, and back
Nausea and vomiting
Rapid or worm-like movements of the tongue
Tic-like or twitching movements
Trembling and shaking of the hands and fingers
Twisting movements of the body
Uncontrolled chewing movements
Uncontrolled movements of the arms and legs
Weakness of the arms and legs
Yellow eyes or skin

\section{DISCUSSION}

The reason for our patient's initial dizziness, nausea and vomiting is not certain, but may have been a combination of rough seas, acute gastroenteritis and alcohol. The dopamine antagonist metoclopramide has both central (antidopamine-2 anti-serotonin 5-HT3) and peripheral (serotonin 5-HT4-antagonistic) properties. The former is deemed to reduce nausea and the latter to promote coordinated gastric propulsion, both quite desirable effects in motion sickness [1]. Medication by mouth does not work when vomiting has started. Although parenteral antiemetic medication has not been properly tested for vomiting at sea, metoclopramide has since the 1970s been the antiemetic drug-of-choice for adults on vessels with Scandinavian ship's doctors and nurses [1]. Uniform striking relief of debilitating seasickness is usually seen within minutes after slow intravenous administration of $10 \mathrm{mg}$ of metoclopramide, and side effects have not been considered a problem on cruise ships. While some patients have reported mild fatigue after the injection, the sedative effect appeared to be far less than after pro- 
methazine. Promethazine is an antihistamine widely used at sea as a parenteral antiemetic, after which sedation is considered therapeutic ('a blessing!') by seasick passengers who just want to 'sleep it off', preferably until the next port.

One possible reason for not seeing more side effects on cruise ships might be that single metoclopramide injections are usually followed up by meclizine tablets once the urge to vomit had subsided. A widely used and well-documented antihistamine used against nausea and vertigo, meclizine has similar anticholinergic effects as diphenhydramine, which is recommended for extrapyramidal symptoms and for overdose from metoclopramide [4].

However, our patient received both intramuscular metoclopramide and intramuscular diphenhydramine at the same time because of vertigo, nausea and vomiting. Vomiting stopped, but the dizziness persisted and was treated with low-dose metoclopramide by mouth. Metoclopramide was stopped after 4 days, during which she had taken a total of $30 \mathrm{mg}$. Despite this low total dose over an ultra-short period (lower dose and shorter duration than considered acceptable by the European Union Committee [2] and US Food and Drug Administration (FDA) [4]), she experienced a plethora of very upsetting neurologic side effects that haunted her almost daily for about 10 months. Diphenhydramine and biperiden have been reported to be effective treatments for acute metoclopramide-induced dystonia or akathisia [5-9]. Initially diphenhydramine helped our patient to sleep, but it did not have any noticeable effect on her long-term extrapyramidal symptoms and tardive dyskinesia.

Although she realised that her suicidal and depressive thoughts, as well as her 'out-of-her-body experiences' were not real, they were very frightening and she was greatly bothered by her involuntary body movements.

Despite slow, but steady general improvement, she was constantly worried about the 'Black Box Warning' that she found on the Internet. Issued by US FDA in 2009, it states that "In some patients, symptoms may lessen or resolve after metoclopramide treatment is stopped. (...) metoclopramide can cause tardive dyskinesia, a serious movement disorder that is often irreversible. (...) There is no known treatment (...)" [4]. Adverse effects after metoclopramide on land are well known, but are mostly seen after high doses and longterm use. The absolute risk of metoclopramide-induced tardive dyskinesia remains unknown, but is likely to be less than $1 \%$ even after long-term treatment [10]. The US FDA 'Black Box Warning' recommended that indications for metoclopramide use should be limited and treatment should not exceed 3 months [4]. Unspecified nausea and vomiting is still an indication for metoclopramide use approved by the Norwegian Medicines Authority [11], but with a link to the European Union Committee 2013 statement advising against use of daily doses exceeding $30 \mathrm{mg}$ and treatment duration of more than 5 days [12]. It is not clear why our previously healthy patient who used no medication or drugs developed a plethora of long-lasting disturbing adverse effects despite lower doses and shorter duration than that.

Seasick travellers are often rather mocked than pitied by the unaffected, but on ships seasickness is a serious condition that must be treated as an emergency - promptly, safely and effectively [1]. Seasick marine staff members represent a serious safety hazard, while affected hotel crew will provide poor or no service. Sustained vomiting can cause severe dehydration and is life threatening in persons who depend on per oral medications. Ineffective treatment will ruin a cruise for the passengers and may keep them from booking further cruises. There is no international agreement on seasick medications, and the indications for the various drugs vary within the European Union [2] and around the world [1]. Some medications that are considered drug-of-choice in some countries may be banned or not registered at all in another country [1]. Safe and effective parental remedies for severe seasickness are particularly important for pregnant women and watch-going seafarers, which calls for further research.

\section{CONCLUSIONS}

Our case is particularly disturbing for ship's doctors who have successfully treated numerous distressed sea travellers over the years with a single parenteral dose of metoclopramide. When feeling in dire need of antiemetic medication, patients on ships are usually not very motivated for discussing side effects. It will therefore be mostly up to the physician to carefully weigh potential benefits against possible risks after considering contraindications and warnings. At this point metoclopramide should be reserved for debilitating cases - and only be given after other remedies have been tried and found ineffective.

\section{REFERENCES}

1. Wolffgram T. Motion sickness. In: Carter T, Schreiner A eds. Textbook of maritime medicine (V2 2013). http://textbook.ncmm.no/maritime-health-risks-and-consequences/20-motion-sickness (accessed 17 January 2014).

2. European Medicines Agency. European Medicines Agency recommends changes to the use of metoclopramide. Press release 26 July 2013 (EMA/443003/2013) http://www.ema.europa.eu/ ema/index.jsp?curl=pages/news_and_events/news/2013/07/ news_detail_001854.jsp\&mid=WC0b01ac058004d5c1 (accessed 17 January 2014).

3. The U.S. National Library of Medicine. Metoclopramide Side Effects. http://www.ncbi.nlm.nih.gov/pubmedhealth/ /PMH0044845/\#DDIC600921.side_effects_section (accessed 17 January 2014).

4. Reglan injection (metoclopramide injection, USP). Reference ID: 2863020. Baxter Healthcare Corporation, IL 60015, USA, revised November 2010 http://www.accessdata.fda.gov/drugsatfda_docs/ label/2010/017854s055lbl.pdf (accessed 17 January 2014). 
5. Van der Padt A, van Schaik RHN, Sonneveld P. Acute dystonic reaction to metoclopramide in patients carrying homozygous cytochrome P450 2D6 genetic polymorphisms. Neth J Med 2006; 64: 160-162.

6. Qui LM, Lim BL. Case of acute akathisia from intravenous metoclopramide. Singapore Med J 2011; 52: e12.

7. Chauhan G, Nayar P, Kashyap C. Metoclopramide-induced akathisia. J Anaesthesiol Clin Pharmacol 2012; 28: 548-549.

8. Karimi Khaledi M, Suda KJ, Shelton CM. Tardive dyskinesia after short-term treatment with oral metoclopramide in an adolescent. Int J Clin Pharm 2012; 34: 822-824.
9. Silfeler I, Arica V, Arica S, Dogan M. Development of acute dystonia in three brothers due to metoclopramide. J Res Med Sci 2012; 17 : 308-309.

10. Rao AS, Camilleri M. Review article: metoclopramide and tardive dyskinesia. Aliment Pharmacol Ther 2010; 31: 11-19.

11. Afipran (Takeda Nycomed). Felleskatalogen 2014. http://www. felleskatalogen.no/medisin/afipran-takeda-nycomed-545798 (accessed 05 February 2014).

12. Norwegian Medicines Agency. Varsel fra Legemiddelverket: http:// www.legemiddelverket.no/Nyheter/Bivirkninger/Sider/Nye-anbefalinger-ved-bruk-av-metoklopramid.aspx (accessed 05 February 2014). 